\title{
Acesso às tecnologias educacionais em instituições públicas: os desafios de inovar em tempos de pandemia no Brasil
}

Access to educational technologies in public institutions: the challenges of innovation in pandemic times in Brazil

Acceso a las tecnologias educativas em las instituciones públicas: los desafios de la innovación em tempos de pandemia em Brasil

Ádina Ferreira de Souza

ORCID: https://orcid.org/0000-0001-5426-2995 Universidade Federal do Vale do Jequitinhonha e Mucuri, Brasil E-mail: adinasouza09@hotmail.com

Cláudio Gomes de Moraes

ORCID: https://orcid.org/0000-0003-1585-1767

Universidade Federal do Vale do Jequitinhonha e Mucuri, Brasil E-mail: claudiomoraes75@gmail.com

Marcio Coutinho de Souza

ORCID: https://orcid.org/0000-0002-4238-1572

Universidade Federal do Vale do Jequitinhonha e Mucuri, Brasil E-mail: marcio.souza@ufvjm.edu.br

Mauro Lúcio Franco

ORCID: https://orcid.org/0000-0003-2114-4399

Universidade Federal do Vale do Jequitinhonha e Mucuri, Brasil E-mail: ml.franco@ufvjm.edu.br

Lorena Sophia Campos de Oliveira

ORCID: https://orcid.org/0000-0003-0704-1828

Universidade Federal do Vale do Jequitinhonha e Mucuri, Brasil E-mail: lorena.oliveira@ufvjm.edu.br

Alexandre Sylvio Vieira da Costa ORCID: https://orcid.org/0000-0001-7251-7816 Universidade Federal do Vale do Jequitinhonha e Mucuri, Brasil E-mail: alexandre.costa@ufvjm.edu.br

Magnum Moreira da Silva ORCID: https://orcid.org/0000-0001-8797-1819 Universidade Federal do Vale do Jequitinhonha e Mucuri, Brasil E-mail: magnum.moreira@ufvjm.edu.br

Raquel de Souza Pompermayer ORCID: https://orcid.org/0000-0002-2455-3027 Universidade Federal do Vale do Jequitinhonha e Mucuri, Brasil E-mail: raquel.pomper@ufvjm.edu.br

\begin{abstract}
Resumo
A pandemia COVID-19, evidenciou as dificuldades encontradas no ensino e tornou necessária uma inovação, principalmente nas instituições públicas em todo o Brasil. Ao realizarmos essa pesquisa, utilizamos uma coleta de amplo material bibliográfico com o objetivo de identificar as dificuldades e necessidades de alunos e professores para se adaptarem e inovarem na educação em meio ao isolamento social. Apresentamos a educação no Brasil e as dificuldades de professores e alunos dentro do processo educacional, abordando suas realidades em meio a tecnologia disponível, a disponibilização de internet e sua disponibilidade aos alunos, discutindo a grande lacuna educacional gerada pela exclusão digital oriunda de condições socioeconômicas desfavoráveis. Observou-se que inovar na educação, seja em tempos de pandemia ou em qualquer tempo, só é possível com a definição de políticas públicas assertivas que respeitem as pluralidades e capacidades de alunos e professores, baseadas na disponibilidade do acesso a internet e melhor distribuição de emprego e renda.
\end{abstract}

Palavras-chave: Educação; Exclusão digital; Políticas públicas; Professor; Aluno; Pandemia.

\section{Abstract}

The COVID-19 pandemic highlighted the difficulties related to teaching and demanded innovation, especially in public schools and universities throughout Brazil. In this research, it was performed an extensive literature review in 
order to identify the difficulties and needs of students and teachers to adapt and innovate in education amidst social isolation. This paper presents education in Brazil and the struggles of the teachers and students within the educational process, addressing their realities regarding available technology, the accessibility to of the internet and its availability to students, discussing the large educational gap generated by the digital exclusion arising from unfavorable socioeconomic conditions. It was observed that innovating in education, whether in times of pandemic or at any time, is only possible with the drafting of assertive laws and public policies that respect the plurality and capacities of students and teachers, based on the availability of internet access and better distribution of employment and income.

Keywords: Education; Digital exclusion; Public policy; Teacher; Student; Pandemic.

\section{Resumen}

La pandemia COVID-19 puso de relieve las dificultades encontradas en la enseñanza e hizo necesaria la innovación, especialmente en las instituciones públicas de todo Brasil. Al realizar esta investigación, utilizamos una colección de extenso material bibliográfico con el fin de identificar las dificultades y necesidades de estudiantes y docentes para adaptarse e innovar en la educación en medio del aislamiento social. Presentamos la educación en Brasil y las dificultades de los docentes y estudiantes dentro del proceso educativo, abordando sus realidades en medio de la tecnología disponible, la disponibilidad de internet y su disponibilidad para los estudiantes, discutiendo la gran brecha educativa que genera la exclusión digital derivada de condiciones socioeconómicas desfavorables. Se observó que innovar en educación, ya sea en tiempos de pandemia o en cualquier momento, solo es posible con la definición de políticas públicas asertivas que respeten las pluralidades y capacidades de estudiantes y docentes, basadas en la disponibilidad de acceso a internet y una mejor distribución de la empleo e ingresos.

Palabras clave: Educación; Exclusión digital; Políticas públicas; Profesor; Aluno; Pandemia.

\section{Introdução}

As Tecnologias vêm transformando o mundo ao longo dos anos, impactando diretamente a forma de vida, seja no trabalho, no lazer ou nas atividades do cotidiano. A tecnologia está presente e não poderia ser diferente na educação. O ensino superior à distância, por exemplo, já é uma realidade, demonstrando a sua funcionalidade para aqueles que não têm tempo de participar das aulas presenciais.

Entretanto, as condições precárias da educação no Brasil, não é uma novidade, falta investimento em estrutura, melhores condições socioeconômicas dos alunos e dos professores, ou seja, baixos investimentos são uma realidade da educação brasileira. Além disso, a educação no país, possui uma grande defasagem na qualidade do ensino, principalmente na educação básica, essa realidade tende a piorar quando esta educação é transferida para os canais online sem as devidas providências e investimentos para essa modalidade de ensino. As tecnologias, bem como, a internet é uma realidade para todos os povos no mundo inteiro, mas observa-se no âmbito nacional que a dificuldade de acesso pelos alunos ainda é um problema que precisa ser tratado adequadamente (Carneiro \& et al., 2020; Castro \& Leite, 2006).

A falta de preparo dos professores no manuseio das tecnologias educacionais e as dificuldades dos alunos ao acesso à internet e aos meios tecnológicos básicos para acesso ao conteúdo, acarretaram problemas de grandes proporções (Oliveira \& Passos, 2008). Assim, a falta de investimento em aprimoramento das metodologias, estrutura e atualização dos professores, se tornou um agravante ainda maior neste momento de pandemia.

Desta forma, é necessária a realização da pesquisa, tendo em vista que a pandemia intensificou diversos problemas. Nas instituições públicas de ensino superior, por exemplo, a tecnologia está presente nos portais, para acompanhamento e lançamento das notas, na biblioteca, no moodle para envio de atividades complementares, entre outros. Mas esse nível de ensino manteve-se primordialmente como presencial, apesar das tecnologias disponíveis. Contudo, no advento da pandemia da COVID19 vivenciada nos últimos anos, todos os níveis de ensino precisaram sofrer adequações tornando o acesso às tecnologias educacionais em instituições públicas um grande desafio, dentre eles, a dificuldade no manuseio das Tecnologias da informação e comunicação (TICs) entre professor e aluno dos níveis fundamental, médio e superior, destacando agravantes que já existiam (Carneiro \& et al., 2020; França \& et al., 2019; Pinto, 2004).

Diante desta realidade, este artigo tem como problema de pesquisa: 
- Quais os desafios na utilização das TICs para inovar no processo de ensino aprendizagem em tempos de pandemia nas instituições públicas de ensino?

Vale destacar que, as estruturas destas instituições foram planejadas para o ensino presencial e com o advento da COVID19, o contato presencial se tornou 'proibido' por medidas de segurança. Desta forma, uma 'remodelagem' se fez necessária para que as atividades possam dar continuidade.

O objetivo desta pesquisa é identificar os desafios que as instituições públicas de ensino estão enfrentando, bem como os seus usuários (professor e aluno) diante desta nova realidade, haja vista que os problemas com a educação que já existiam, tornaram-se um agravante ainda maior associada a dificuldades de acessos às tecnologias educacionais.

Este artigo está dividido nas seguintes seções: Educação no Brasil e as dificuldades professor e aluno no processo educacional, abordando sobre realidade destes personagens em seu cotidiano; Trata também das tecnologias educacionais apresentando a importância das tecnologias para a educação; Discute sobre a internet como um dos recursos fundamentais no processo de desenvolvimento da sociedade e como recurso educacional; Destaca como a exclusão digital interfere no processo de desenvolvimento social; Discute o processo de ensino aprendizagem e as TICs; Considerações finais e referências.

\section{Metodologia}

Para este trabalho realizou-se a pesquisa do tipo exploratória e aplicada, tendo em vista que Gil (2017), disserta que a tipificação exploratória diz respeito a estudar o assunto e adquirir uma maior familiaridade com o problema estudado e decodificá-lo de forma a contribuir com o ganho de conhecimento. Já a pesquisa aplicada possui o objetivo de adquirir conhecimento para aplicar nas situações e justificativas encontradas para sua utilização.

A pesquisa possui a característica bibliográfica, onde foram analisados os diversos estudos existentes no meio acadêmico sobre o assunto. De acordo com Lima e Mioto (2007, p. 38) "a pesquisa bibliográfica implica em um conjunto ordenado de procedimentos de busca por soluções, atento ao objeto de estudo, e que, por isso, não pode ser aleatório". A mesma também pode ser considerada qualitativa pois segundo Neves (1996) possui como característica o direcionamento, não possui como objetivo enumerar ou medir eventos, não havendo análise estatística, apresentando uma análise ampla se diferenciando da análise quantitativa.

Procedemos a coleta de material bibliográfico com o objetivo de identificar as dificuldades dos alunos e professores para se adaptarem a esse novo cenário criado pela pandemia, relacionando as tecnologias disponíveis e expor as deficiências brasileiras, principalmente as socioeconômicas que têm impactado negativamente o processo de ensino-aprendizagem.

\section{Referencial Teórico}

Esta seção apresenta, inicialmente, as dificuldades do professor e aluno no processo educacional, no intuito de apresentar os problemas enfrentados mesmo antes da pandemia. Em seguida será apresentada a importância das tecnologias educacionais e da internet para a educação, entendendo o que é exclusão digital para que em seguida possamos compreender como se dá o processo ensino-aprendizagem.

\subsection{Educação no Brasil: dificuldades professor e aluno no processo educacional}

A educação no Brasil sofreu mudanças significativas após a promulgação da constituição de 1988 que instituiu em seu art. $6^{\circ}$ o direito "à educação, a saúde, a alimentação, o trabalho, a moradia, o transporte, o lazer, a segurança, a previdência social, a proteção à maternidade e à infância, a assistência aos desamparados" (Brasil, 1988, p. 6), garantindo assim a educação para "todos" de forma gratuita. 
No entanto, mesmo com estas garantias, muitas dificuldades permanecem. As questões socioeconômicas dos alunos, por exemplo, lideram o ranking de problemas, pois existe uma parcela da população que não possui acesso à educação por dificuldades financeiras dentro de casa. Ney, Souza e Ponciano (2010) também afirmam que a desigualdade econômica e a pobreza estão fortemente ligadas ao desempenho educacional do aluno na escola. Além das dificuldades, tais como locomoção, o aluno ainda encontra precariedade quanto a estrutura da instituição de ensino e acesso ao material didático, que muitas vezes é compartilhado.

A desigualdade entre os jovens é grande, uma vez que muitos deixam as escolas para trabalhar e contribuir no sustento da própria família. De acordo com Castro (2009, p. 688):

Além de ainda haver uma porcentagem residual de crianças e jovens fora da escola, entre os matriculados há os que não aprendem ou que progridem lentamente, repetem o ano e acabam abandonando os estudos. Os fatores que contribuem para essas dificuldades estão relacionados à qualidade do ensino, à gestão das escolas e sistemas de ensino, às condições de acesso e permanência e às desigualdades sociais dos próprios alunos e de seus familiares.

A evasão dos alunos impacta no processo econômico do país, pois os mesmos podem ter capacidade para desenvolver atividades manuais, no entanto podem apresentar dificuldades em desenvolver atividades técnicas, que necessitam de um conhecimento teórico, impactando na oferta de mão de obra especializada Ney, Souza e Ponciano (2010). No desenvolvimento educacional do Brasil é possível perceber o grande acúmulo de cargos por parte dos professores da educação básica, uma vez que o salário médio oferecido impossibilita condições básicas para que o mesmo possa se dedicar. Desta forma, o acúmulo de cargos acarreta volume de trabalho que por sua vez gera dificuldades em se profissionalizar e/ou aprimorar os seus conhecimentos. Pavan e Backes (2016, p. 40) afirmam que "as políticas neoliberais intensificaram o trabalho docente. No contexto brasileiro, há décadas o professor da escola básica, muitas vezes, se vê obrigado a trabalhar três turnos e em várias escolas, dadas as condições salariais".

Com as dificuldades em se profissionalizar, vale destacar que em alguns casos os professores não têm acesso, apresentam dificuldades ou medo no manuseio dos meios tecnológicos (Chiofi \& Oliveira, 2014), o que atrapalha na didática e metodologia, criando entraves na extensão do conhecimento. As condições de trabalho proporcionadas aos professores impossibilitam aulas que saem do cotidiano, sem infraestrutura e suporte adequado que afetam o trabalho do professor e consequentemente o rendimento dos alunos, pois acabam proporcionando aulas monótonas, sem os artifícios necessários que possibilitem uma melhor aprendizagem.

Castro e Leite (2006) Acredita que a evasão escolar não pode ser única e exclusivamente "culpa" da necessidade de trabalhar para garantir o sustento, mas levanta a hipótese também de um crescimento da falta de interesse em aprender por parte dos alunos. Segundo os autores existem casos "[...] de que a rejeição à escola é mais forte do que a atração pelo trabalho" (Castro \& Leite, 2006, p. 141). Ao longo dos anos a evasão tem deixado de ser um problema de acesso dos alunos à escola, mas sim as dificuldades em mantê-los.

Além do grande acúmulo de cargos e salário precário, o professor se expõe ao risco da violência em sala de aula, acarretando problemas de saúde físicos e psicológicos como por exemplo a síndrome de Burnout como retrata Leite e Souza (2011) uma doença decorrente de uma exaustão física e/ou emocional de repetidas situações estressantes. Com isso muitos se afastam do cargo ocasionando outro problema que é a substituição por outro profissional que possua currículo compatível com as exigências, neste momento a instituição enfrenta o problema de mão de obra especializada que tenha condições e aceite, na maioria das vezes não querem, trabalhar dentro daquelas condições de trabalho, ocasionando assim uma substituição por profissionais que possuem especialização similar, ou seja, que possua dentro da sua grade curricular de formação, disciplinas que possam ser consideradas bases e que dê condições para ministrar o conteúdo da disciplina. 
Como destaca Aranha (2007 apud Oliveira \& Passos, 2008) sobre professores eventuais que atuam nas escolas públicas no interior de São Paulo revela que essa figura de substituto ou eventual vem atuando de maneira crescente nas escolas e ministrando qualquer disciplina em classes de $5^{\mathrm{a}}$ a $8^{\mathrm{a}}$ séries, sem possuir a habilitação necessária para substituir o professor ausente. A investigação aponta para a fragilização e desprofissionalização do trabalho docente e indica que as atividades do eventual, da forma como vem acontecendo, materializam a descaracterização do trabalho docente.

Com isso, mesmo o aluno permanecendo em sala de aula, tende a se prejudicar com relação ao conteúdo e a metodologia que será utilizada por esses profissionais na ministração das aulas, pois são profissionais que se prepararam para exercer a sua profissão e não tiveram preparo para desempenhar atividades pedagógica.

\subsection{Tecnologias educacionais}

As tecnologias a cada dia levam informações a um número grande de pessoas, de maneira rápida e por meios variados. Dentre os nichos que utilizam os canais tecnológicos está a educação. As tecnologias educacionais possuem um papel importante em sala de aula no sentido de inovar as metodologias de ensino, conforme relata Pinto (2004, p. 4) "usar tecnologia tem como objetivo o aumento da eficiência da atividade humana em todas as esferas, principalmente na produtiva".

Se as tecnologias facilitam o acesso a pesquisas no âmbito acadêmico, com as crianças e adolescentes do mundo atual não seria diferente. Os Alunos de nível fundamental e médio estão rodeados de meios tecnológicos aos quais interagem com um mundo de informações, desta forma utilizar as tecnologias educacionais trata-se de aproveitar a oportunidade e chamar a atenção destes jovens e adolescentes para um aprendizado com mais qualidade. Chiofi e Oliveira (2014, p. 330) destacam que "as novas tecnologias permitem aplicabilidades pedagógicas inovadoras que podem contribuir para resultados diferenciados, bem como fortalece a justiça social, pela democratização do acesso ao ensino, permitindo pelo processo da comunicação tecnológica que todos se apropriem do conhecimento".

Desse modo, o autor ainda destaca que é necessário que os profissionais da educação ressignifiquem e inovem a sua didática para a transferência do conhecimento de modo a valorizar o processo de produção do mesmo. Gasque \& Costa (2003, p. 3) destacam que "as novas tecnologias da informação são, ao mesmo tempo, recurso para a formação do professor e para a elaboração de estratégias de ensino e aprendizagem".

Dentre as ferramentas educacionais que podem ser trabalhadas Carneiro et al. (2020, p. 9) destaca as seguintes: Google, Google Classroom, Google Suite, Google Hangout, Google Meet, Facebook, OneNote from Microsoft, Microsoft, SEQTA, Perfect Education, Google Drive/Microsoft Teams, Moodle, Zoom, Seesaw, ManageBac, ManageBac, Ed Dojo EdModo, Mediawijs, Youtube, Whatsapp, Ebscohost, Progrentis, PhET, Screencastify, RAZ Kids e IXL.

As ferramentas citadas pelo autor se trabalhadas da maneira correta, atreladas às metodologias adequadas, acesso à internet de qualidade, se tornam um grande aliado do professor e propulsores do conhecimento. Não se pode falar de ferramentas tecnológicas sem destacar a internet, que sem dúvida na grande maioria das ferramentas é o motor para que estes instrumentos possam fazer o seu papel com excelência. Ter uma internet de qualidade é de suma importância.

“A Internet tem sido cada vez mais incorporada ao cotidiano das pessoas, representando um avanço quanto à formação continuada em todas as áreas, uma vez que proporciona e integra várias ferramentas e recursos diversificados, principalmente para a formação docente" (Gasgue \& Costa, 2003, p. 3). Saber utilizar as tecnologias educacionais pode se tornar um diferencial frente ao mercado, o profissional da educação se destaca. Silva, David e Mantovani (2015) destaca que ao longo dos anos o uso das TICs no ensino básico vem se tornando cada dia mais essencial.

A introdução das novas tecnologias nas salas de aula facilita as trocas interindividuais. As informações se tornam mais acessíveis, os professores deixam de ser o mestre "sabe tudo" e os materiais pedagógicos evoluem de livros-textos para programas e projetos mais amplos. A capacitação do professor para docência em novas tecnologias requer uma nova 
configuração do processo didático e metodológico para uma formação adequada e propostas inovadoras. As novas tecnologias precisam estar integradas em ambientes de ensino-aprendizagem, em situações que permitam ao aluno o envolvimento com os processos de aprendizagem necessários para atingir os objetivos educacionais desejados (Ribas, 2008, p. 7).

Com o advento da pandemia do COVID-19 as ferramentas tecnológicas ganharam mais notoriedade, nunca se buscou tanto tecnologias que proporcionem meios para a continuidade do ensino. O processo de ensino e aprendizagem se transforma nesse contexto. As formas habituais de lecionar precisam ser revistas. É preciso modificar o planejamento pedagógico e encontrar alternativas para envolver, motivar e propiciar o desenvolvimento dos estudantes, mesmo que a distância (Silva, 2020).

Muitas ferramentas conhecidas, mas pouco utilizadas por ambas as partes (professor e aluno), o que acarretou uma descoberta, pois infelizmente ainda existe uma resistência quanto às tecnologias educacionais. França \& et al. (2019), retrata que os cursos de licenciatura no Brasil não preparam o professor para utilizar as tecnologias em seu cotidiano em sala de aula.

Vale ressaltar que a pandemia trouxe desafios para além deste momento, apenas reforçou que o professor deverá repensar metodologia de ensino para além do home office (momento em que se vive o distanciamento social), mas em levá-lo para a sala de aula, por se tratar de um assunto que também chamou a atenção dos governos, que indiretamente estão vendo na prática a funcionalidade de tais ferramentas, é diante dessa crescente importância que as TICs conquistando espaços nos feitos sociais dentro dos contextos escolares, bem como, ganhando os espaços nas legislações vigentes, para garantir a qualidade de ensino (Barros \& et al., 2020).

\subsection{Internet}

Para Bell (1974), as mudanças que ocorriam naquela época, foi uma mudança de caráter do próprio conhecimento, estruturado em um novo poder em que toda a sociedade vive agora pela inovação e pelo desenvolvimento, dando corpo a "novos homens", cientistas, matemáticos, economistas e engenheiros da nova tecnologia industrial. De acordo com ele, houve o nascimento de uma nova sociedade, uma que veio para ficar, eliminando a sociedade pós-industrial e a substituindo pela sociedade da informação. Masuda (1982), acreditava que o computador expandiria o poder produtivo da informação, ocasionando uma produção automatizada em massa da informação, tecnologia e conhecimento cognitivos baseada numa alta criatividade intelectual. Ele usou o termo Sociedade da Informação, conceituado que: “[...] é uma sociedade baseada na alta criatividade intelectual, onde as pessoas podem desenhar os projetos numa tela invisível, bem como perseguir e alcançar a sua auto-realização" (Masuda, 1982, p. 19).

Já era previsto que teríamos uma sociedade da informação que ocuparia um novo setor, o quaternário. A internet é um recurso que possui diversas aplicações educacionais que estão contribuindo para o desenvolvimento da educação, Moran (1997), cita vários recursos da internet, como a divulgação que coloca a escola e suas informações institucionais, biblioteca, corpo docente, discente entre outros, para o usuário da informação. Ele elenca ainda os recursos de pesquisa, que se tornam abrangentes e multivariados; o apoio ao ensino, que torna as aulas mais dinâmicas, interativas com a utilização de sons e imagens, revistas digitais, vídeos que tornam o ensino mais fluido. Os recursos de comunicação, salas de aula remotas, listas e grupos de discussão, encontros virtuais, grupos de trocas de informação que contribuem para uma nova visão para as barreiras de tempo e espaço. Alegando ainda que:

Professores e alunos se relacionam com a Internet, como se relacionam com todas as outras tecnologias. Se são curiosos, descobrem inúmeras novidades nelas como em outras mídias. Se são acomodados, só falam dos problemas, da lentidão, das dificuldades de conexão, do lixo inútil, de que nada muda. Ensinar na e com a Internet atinge resultados significativos quando se está integrado em um contexto estrutural de mudança do processo de ensinoaprendizagem, no qual professores e alunos vivenciam formas de comunicação abertas, de participação interpessoal e 
grupal efetivas. Caso contrário, a Internet será uma tecnologia a mais, que reforçará as formas tradicionais de ensino. A Internet não modifica, sozinha, o processo de ensinar e aprender, mas a atitude básica pessoal e institucional diante da vida, do mundo, de si mesmo e do outro (Moran, 1997, p. 7).

A Internet é o veículo que tem impulsionado o desenvolvimento tecnológico, tendo em vista que a tecnologia não pode ser ignorada. Ela está presente em nosso modo de vida, que nos permite projetar e adequar nossas cidades, na configuração dos sistemas de transporte, dos meios de comunicação, agricultura e produção industrial. Nossas escolhas estão direcionando a confiança e o desenvolvimento da educação e da saúde (Feenberg, 2010).

Vivemos na era tecnológica, embora a construção do conhecimento científico não esteja atrelada ao uso de recursos tecnológicos, é inegável que eles contribuem significativamente para o desenvolvimento científico, tendo em vista que eles podem gerar inúmeras contribuições para o desenvolvimento do trabalho em equipe em um ambiente de forma crítica e criativa, gerando informações que viabilizem o relacionamento entre as ciências e a elaboração de projetos capazes de viabilizar projetos que envolvam transdisciplinaridade e interdisciplinaridade (Arenare \& Mól, 2020, p. 5).

O aparecimento das redes eletrônicas não aumenta o isolamento, nem prejudica a sociedade, a cultura e as relações humanas; pelo contrário, constata-se que as TICs são úteis para estimular as cooperações, partilhar conhecimentos e ideias, desenvolver parcerias e enriquecer as atividades. A Internet proporciona novos hábitos, práticas de trabalho, estudo, lazer, consumo e procura de informação. De acordo com a Pesquisa Nacional por Amostra de Domicílios (PNAD) de 2019, 82,7\% dos domicílios brasileiros têm acesso à internet.

\subsection{Exclusão digital}

Conceber a ideia que a inclusão digital é formada a partir da utilização das tecnologias é colocar uma venda nos olhos para a realidade, pois, incluir é tratar a participação do sujeito como importante e essencial de forma que ele possa ser um produtor de cultura e de conhecimento, conforme afirma Bonilla (2004, p. 19):

Romper com essa perspectiva implica extrapolar o reducionismo feito ao conceito de inclusão digital e abordá-lo na perspectiva da participação ativa, da produção de cultura e conhecimento, o que implica políticas públicas que invistam efetivamente na capacitação dos professores, oportunizando condições para questionar, produzir, decidir, transformar, participar da dinâmica social em todas as suas instâncias, bem como trabalhar com seus alunos nessa perspectiva.

Partindo de uma análise econômica, ao tentar tratar um novo modelo para a gestão da inteligência, é importante verificar que a alienação a que a sociedade está exposta tem um forte impacto na exclusão digital, que segundo Cavalcanti \& Gomes (2001, p. 53):

A economia do Conhecimento desloca o eixo da riqueza e do desenvolvimento de setores industriais tradicionais intensivos em mão-de-obra, matéria-prima e capital - para setores cujos produtos, processos e serviços são intensivos em tecnologia e conhecimento. Mesmo na agricultura e na indústria de bens de consumo e de capital, a competição é cada vez mais baseada na capacidade de transformar informação em conhecimento e conhecimento em decisões e ações de negócio. O valor dos produtos depende, assim, cada vez mais, do percentual de inovação, tecnologia e inteligência a eles incorporados. Se antes o que gerava riqueza e poder eram os fatores de produção tradicionais capital, terra e trabalho - hoje, segundo o Banco Mundial, 64\% da riqueza mundial advém do Conhecimento.

Ao analisar a economia dos Estados Unidos e sua crença em um mercado livre, percebe-se o grande aumento das empresas de tecnologia e as formas desiguais de acesso a elas, como afirma Eisemberg (2002, p. 236): 
A exclusão digital possui posição privilegiada nas discussões sobre a Nova Economia nos Estados Unidos por ser um problema que permeia toda a sociedade e que contraria o otimismo em relação à riqueza advinda da era da informação. À medida que os jornais e a mídia falam sobre a expansão econômica e o enorme sucesso da economia ponto.com, a discussão em relação a exclusão digital, se torna ainda mais importante, tendo em vista que a crença norte americana é de um mercado livre, por isso o otimismo em relação à economia, porém, é preocupante que o acesso desigual aos computadores e a internet venham a aumentar as desigualdades de renda e de acesso a oportunidades.

A exclusão digital é atualmente um tema de debates entre governos, organizações multilaterais (ONU, OMC), e o terceiro setor (ONGs, entidades assistencialistas). Políticas de inclusão digital incluem a criação de pontos de acesso à internet em comunidades carentes (favelas, cortiços, ocupações, assentamentos) e capacitação (treinamento) de usuários de ferramentas digitais (computadores, DVDs, vídeo digital, som digital, telefonia móvel). As comunidades carentes, os mais pobres e pessoas com uma posição econômica desprivilegiada são excluídas digitalmente, visto que não possuem acesso à tecnologia. A relação entre exclusão digital e pobreza é uma realidade mundial.

De acordo com o Mapa da Exclusão Digital, que analisou os dados do Censo 2010, o nível de escolaridade é ponto de importância não só na geração de renda, mas também no nível de inclusão digital dos estados brasileiros: os cinco mais incluídos são o Distrito Federal, São Paulo, Rio de Janeiro, Santa Catarina e Paraná, e os quatro mais excluídos são o Maranhão, Piauí, Tocantins e Acre.

\subsection{Processo de ensino e aprendizagem (EA)}

Paulo Freire (1984, p. 6) em seu livro “A máquina está a serviço de quem?”, já questionava o uso das tecnologias no processo de EA: O avanço da ciência e da tecnologia não é tarefa de demônios, mas sim a expressão da criatividade humana, para ele:

Quero saber a favor de quem, ou contra quem as máquinas estão postas em uso. Então, por aí, observamos o seguinte: não é a informática que pode responder. Uma pergunta política, que envolve uma direção ideológica, tem de ser respondida politicamente. Para mim os computadores são um negócio extraordinário. O problema é saber a serviço de quem eles entram na escola.

Para Valente (1993), o professor deixará de ser o repassador do conhecimento para ser o criador de ambientes de aprendizagem e facilitador do processo pelo qual o aluno adquire conhecimento. De acordo com Behrens (1998), na década de 1990 era evidente o uso de práticas pedagógicas autoritárias e conservadoras, e a ausência de uma postura reflexiva sobre a ação docente. Naquela época já existia a dificuldade para sensibilizar e mobilizar professores para o envolvimento em projetos pedagógicos que promovam esse tipo de reflexão. Na ocasião já se destacava como desafios principais, a profissionalização do professor, a qualificação pedagógica e a sua aproximação a metodologias de ensino inovadoras e transformadoras.

O processo de ensino e aprendizagem é um processo complexo e sempre foi assim, sendo um erro tentar simplificá-lo, já no início do século 21, Wilhelm (2002, p. 238), sobre as lacunas da capacidade humana e das falhas tecnológicas, afirmava que:

A quantidade de hardware, ou a velocidade do microprocessador, são indicadores necessários, mas que não permitem mensurar o grau de participação das pessoas na economia da era da informação. Uma arena onde essa simplificação tem ocorrido é em relação ao indicador-chave que mede o progresso das tecnologias educacionais nas salas de aula. $\mathrm{O}$ fato de conectar as escolas K-12 (do kindergarden ao $12^{\circ}$ ano escola, o que corresponderia no Brasil as escolas de educação infantil até o ensino médio) a internet tem sido alardeada como o ponto alto do avanço da tecnologia educacional. No entanto, esta meta nos diz muito pouco sobre onde esses computadores estão localizados, como os alunos estão fazendo uso deles, os alvos da educação, o treinamento dos professores e a pedagogia. Conhecer o contexto maior em que se situam os avanços da tecnologia da informação pode nos conduzir muito além das soluções 
do tipo "tamanho único", incluindo em nossa equação as lacunas da capacidade humana e também das falhas tecnológicas.

Perrenoud (2000) já afirmava que, dentre outras qualidades essenciais para a qualidade do ensino, o professor deve conceber e fazer evoluir os dispositivos de ensino, saber trabalhar em equipe, participar da criação e da execução do projeto pedagógico da escola, utilizar novas tecnologias em benefício da educação, cuidar da própria formação contínua e ter compromisso com a aprendizagem coletiva e individual. As concepções das modernas pedagogias já apontavam na direção da aprendizagem ativa, do trabalho coletivo, da participação, da pesquisa e da construção do conhecimento (Amaral, 2010). Para Moran (2007), as tecnologias não substituirão os professores, mas irão permitir que várias tarefas e funções dos mesmos possam ser transformadas, o que pôde ser constatado.

Marchiori e et al. (2011) comentam que o desempenho dos alunos depende da atenção que eles dedicam aos estudos. Ainda de acordo com as autoras, essa atenção pode ser considerada um dos principais fatores para o sucesso na aprendizagem. Propor inovações pedagógicas aos professores é remover a estrutura do trabalho e conscientizar-se de certas interdependências, já que, em geral, não se trata de simples substituições metodológicas, mas de importantes alterações que devem ser vistas dentro da complexidade dos encargos da função do professor e de acordo com suas possibilidades e obrigações de trabalho.

Para Alves Júnior et al. (2011), “o professor deve ser capaz de analisar situações complexas por meio de uma leitura diversificada, saber optar por estratégias adaptadas aos objetivos e às exigências éticas, conhecer várias técnicas e instrumentos para o processo de EA, estruturando-as na forma de abordagens, adaptar rapidamente seus projetos em função da experiência, analisar de maneira crítica suas ações e seus resultados e aprender por meio de avaliação contínua durante toda a sua carreira".

Petry (2006), conceituou que as novas tecnologias estão associadas à utilização do computador pessoal e ao acesso às informações em formato digital (texto, imagem estática e dinâmica e sons). Devido a essa diversidade tecnológica, as TICs podem auxiliar no processo de EA ou dispersar a atenção dos alunos. Para Gesser (2012), as novas tecnologias trouxeram avanços na área da educação, com metodologias empregadas para se fazer ensino, nas diferentes formas de materialização do currículo, de aquisição ou de acesso às informações para a efetivação da aprendizagem.

Diante desta realidade sobre a Pandemia do COVID-19 recomenda-se professor/tutor traga intervenções significativas que promovam a assimilação das informações, de modo que cada indivíduo, usufruindo dos recursos disponíveis em EAD, possa compor cenários em sintonia com os elementos próprios de seu contexto e consiga transformar seu universo intelectual com experiências positivas de aprendizagem (Camacho \& et al., 2020, p. 1).

Hoje não se discute se a escola deve ou não utilizar a tecnologia como ferramenta educacional, pois já é uma realidade no contexto educacional. A questão a ser debatida é como usar essas novas tecnologias de forma eficiente e proveitosa. Dessa forma, é possível o professor se transformar em um estimulador do aprendizado do aluno, despertando nele a curiosidade em conhecer, em pesquisar, e buscar a informação mais relevante.

\section{Considerações Finais}

Ao analisar os aspectos educacionais presentes na prática do ensino implantado nas escolas com a pandemia, foi possível perceber uma série de dificuldades que permeiam o processo de EA, tendo em vista vários fatores, como a exclusão digital, o acesso às tecnologias, a curva de aprendizagem de novas metodologias de ensino, os desafios de obter uma qualidade de ensino em meio a pandemia, as situações socioeconômicas relacionadas aos aspectos emocionais envolvidos na prática do ensino seja ela ligada aos papéis tanto de professores quanto de alunos.

Foi possível perceber que as lacunas do processo de EA criado pela pandemia não são novas e que elas existem há muito tempo separando os alunos com acesso e os sem acesso, mediante as condições socioeconômicas, pois a pobreza 
continua criando uma lacuna cada vez maior nesse processo e consequentemente originando a evasão escolar.

A inserção das novas tecnologias na sala de aula, principalmente a internet e sua disponibilidade, têm possibilitado uma troca de saberes, tendo em vista que as tecnologias empregadas na sala de aula, reduzem barreiras de disponibilidade, contribuem para a inclusão digital de forma plural e consequentemente permitem uma melhoria no processo de EA, transformando a educação clássica numa nova educação, mais assertiva e mais inclusiva com possibilidade de eliminar as barreiras socioeconômicas.

No entanto, observa-se que apesar dos inúmeros benefícios na utilização das TICs no ambiente educacional, existem entraves que dificultam a sua utilização com maior eficiência, como dificuldades de acesso à internet de qualidade por parte dos alunos e professores, problemas socioeconômicos dos alunos, estrutura das instituições de ensino, falta de capacitação adequada dos professores que promovam uma interação maior e uma constante preocupação com o uso das TICs no processo de ensino aprendizagem.

Reaprender a ensinar e reaprender a aprender são desafios em meio ao isolamento social na educação do país (Cordeiro, 2020). Conforme já afirmado, a crise instaurada pela COVID-19, profissionais tiveram o desafio de aprenderem uma nova forma de ministrar aulas, muitas vezes, aprendendo a lidar também com uma forma teológica que não outrora tinha intimidade. Assim, políticas públicas de formação de professores são de extrema importância.

As políticas públicas em inovação educacional precisam ser traçadas levando em conta todo esse cenário atual, visto que o este novo modelo de ensino deve perdurar por todo 2021, ou até mesmo, perdurar boa parte do ano de 2022. Ao elaborar políticas públicas, deve-se compreender e analisar o contexto brasileiro em fatores multifatoriais. É inevitável, a partir de agora, inovar, buscar novas alternativas, aprimorar, conhecer e fazer uso a nosso favor de tudo o que as tecnologias digitais têm a nos oferecer. Necessita-se de políticas públicas e investimento para conseguirmos identificar e ultrapassar os novos desafios a fim de construir novas formas de adquirir conhecimentos.

Contudo é importante não se perder o foco da participação social com investimentos em políticas públicas que venham a permitir a redução da exclusão digital e a eliminação das barreiras socioeconômicas que causam um atraso no desenvolvimento sócio cultural do aluno. Além é claro de políticas públicas voltadas para uma definição de novas formas de ensino, realizando uma transformação do ensino como conhecemos hoje para métodos diferenciados, que respeitem a pluralidade de interesses e capacidades de alunos e professores.

Novos estudos devem ser realizados em busca de uma nova remodelagem do ensino público no Brasil, pois além dos fatores socioeconômicos, gerenciamento adequado dos investimentos governamentais, existe também o fator motivacional e disciplinar por parte dos alunos e cultural por parte da família e sociedade em elevar os níveis de importância para educação conscientizando que abrir mão dos estudos não é a melhor opção apesar das dificuldades.

\section{Referências}

Alves Júnior, J. V., Santo, P. T. E. S., \& Travassos, L. C. P. (2009). Como o bom entendimento da relação entre motivação e aprendizagem pode ser positivo no processo ensino-aprendizagem. Revista Tecer, 2(3). http://dx.doi.org/10.15601/1983-7631/rt.v2n3p54-60

Amaral, A. L. (2010). Significados e contradições nos processos de formação de professores. In: Dalben, A. I. L. F; Pereira, J. E. D; Leal, L. F. V.; Santos, L. L. C. P. (Orgs.). Convergências e tensões no campo da formação e do trabalho docente: didática, formação docente, trabalho docente. Belo Horizonte: Autêntica. (Coleção Didática no Ensino Superior).

Aranha, W. L. A. (2007). Professores eventuais nas escolas estaduais paulista: ajudantes de serviço geral da educação. Araraquara: Unesp. (Mimeo).

Arenare, E. C. C., \& Mól, G. de S. (2020). Contributions of the Media Tools for Inclusion of Students with Disabilities and without Disabilities: analysis of academic records. Research, Society and Development, 9(5), e21953004. https://doi.org/10.33448/rsd-v9i5.3004

Barros, J. L. S., Teles, A. S., Meireles, M. C., Santos, D. V. dos, Silva, F. J. da S., Coutinho, L. R., \& Teixeira, S. S. (2020). Tecnologias de informação e comunicação na base curricular nacional comum para o ensino fundamental: a concepção de professores de São José de Ribamar, Brasil. Research, Society and Development, 9 (7), e482974127. https://doi.org/10.33448/rsd-v9i7.4127 
Behrens, M. A. (1998). A formação pedagógica e os desafios do mundo moderno. Docência na universidade, p. 7.

Bell, D. (1977). O advento da sociedade pós-industrial: uma tentativa de previsão social. Cultrix.

Camacho, A. C. L. F., Joaquim, F. L., Menezes, H. F. de, \& Sant 'Anna, R. M. (2020). A tutoria em educação a distância nos tempos do COVID-19: orientações relevantes. Pesquisa, Sociedade e Desenvolvimento, 9 (5), e30953151. https://doi.org/10.33448/rsd-v9i5.3151

Carneiro, A. L., Rodrigues, W., França, G., \& Prata, D. N. (2020). Uso de tecnologias no ensino superior público brasileiro em tempos de pandemia COVID19. Research, Society and Development, 9, e267985485. http://dx.doi.org/10.33448/rsd-v9i8.5485

Castro, J. A. D. (2009). Evolução e desigualdade na educação brasileira. Educação \& Sociedade, (30), 673-697.

Castro, M. H. D. M., \& Leite, E. M. (2006). Educação no Brasil: atrasos, conquistas e desafios. In: Tafner P. (editor). Brasil: o estado de uma nação, mercado de trabalho, emprego e informalidade, IPEA, p. 121-228.

Cavalcanti, M. \& Gomes, E. (2001). Inteligência Empresarial: Um novo modelo de Gestão para uma Nova Economia. Produção, (10)2, 53-64.

Chiofi, L. C., \& Oliveira, M. R. F. D. (2014). O uso das tecnologias educacionais como ferramenta didática no processo de ensino e aprendizagem. Anais da III Jornada de Didática: Desafios para a docência e II Seminário de Pesquisa do CEMAD.

Cordeiro, K. M. D. A. (2020). O Impacto da Pandemia na Educação: A Utilização da Tecnologia como Ferramenta de Ensino.

Feenberg, A. (2010). Racionalização subversiva: tecnologia, poder e democracia. In: Neder, R. T. (Org.) A teoria crítica de Andrew Feenberg: racionalização democrática, poder e tecnologia. Brasília: Observatório do Movimento pela Tecnologia Social na América Latina / CDS / UnB / Capes. cap.2. p. 69-95.

França, F. F., Costa, M. L. F., \& dos Santos, R. O. (2019). As novas tecnologias de informação e comunicação no contexto educacional das políticas públicas: possibilidades de luta e resistência. ETD-Educação Temática Digital, 21(3), p. 645-661. https://doi.org/10.20396/etd.v21i3.8654687

Freire, P. (1984). A máquina está a serviço de quem? Revista BITS, 6.

Freire, P. (1997b). Pedagogia da Autonomia: saberes necessários à prática educativa. Paz e Terra.

Gasque, K. C. G. D., \& Costa, S. M. D. S. (2003). Comportamento dos professores da educação básica na busca da informação para formação continuada. Ciência da informação, (32), 54-61.

Gesser, V. (2012). Novas tecnologias e educação superior: Avanços, desdobramentos, Implicações e Limites para a qualidade da aprendizagem. IE Comunicaciones: Revista Iberoamericana de Informática Educativa, (16), 23-31.

Leite, M. D. P. \& Souza, A. N. D. (2011). Condições de trabalho e suas repercussões na saúde dos professores da educação básica no Brasil. Educação \& Sociedade, (32), 1105-1121.

Lima, T. C. S. D., \& Mioto, R. C. T. (2007). Procedimentos metodológicos na construção do conhecimento científico: a pesquisa bibliográfica. Revista Katálysis, (10), 37-45.

Masuda, Y. (1982). A sociedade da informação como sociedade pós-industrial. Ed. Rio. 210 p.

Marchiori, L. L. D. M., Melo, J. J., \& Melo, W. J. (2011). Avaliação docente em relação às novas tecnologias para a didática e atenção no ensino superior. Avaliação: Revista da Avaliação da Educação Superior (Campinas), (16), 433-443.

Moran, J. M. (1997). Como utilizar a Internet na educação. Ciência da informação, (26), 146-153.

Ney, M. G., de Souza, P. M., \& Ponciano, N. J. (2015). Desigualdade de acesso à educação e evasão escolar entre ricos e pobres no Brasil rural e urbano. InterSciencePlace, 1(13).

Oliveira, N. D. S. C. \& Passos, L. F., (2008). Professores não habilitados e os programas especiais de formação de professores: a tábua de salvação ou a descaracterização. Revista Diálogo Educacional, 8(23), 105-120.

Pavan, R., \& Backes, J. L. (2016). O processo de (des) proletarização do professor da educação básica. Revista Portuguesa de Educação, $29(2), 35-58$.

Petry, L. C. (2006). O conceito de novas tecnologias e a hipermídia como forma de pensamento. Edições Universidade Fernando Pessoa. Comunidades e Coleções. UFP. http://hdl.handle.net/10284/854

Pinto, M. L. S. (2004). Práticas educativas numa sociedade global. Edições ASA.

Wilhelm, A. (2002). A democracia dividida, a internet e a participação política nos Estados Unidos. In: Cepik, M. \& Eisemberg, J. (Orgs.). Internet e política: teoria e prática da democracia eletrônica. Belo Horizonte: Editora da UFMG. 236-238 